\title{
Coculture Method to Obtain Endothelial Networks Within Human Tissue-Engineered Skeletal Muscle
}

\author{
Dacha Gholobova, Melanie Gerard, Lisanne Terrie, Linda Desender, \\ Janet Shansky, Herman Vandenburgh, and Lieven Thorrez
}

\begin{abstract}
Skeletal muscle tissue engineering aims at creating functional skeletal muscle in vitro. Human muscle organoids can be used for potential applications in regenerative medicine, but also as an in vitro model for myogenesis or myopathology. However, the thickness of constructs is limited due to passive diffusion of nutrients and oxygen. Introduction of a vascular network in vitro may solve this limitation. Here, we describe tissue engineering of in vitro skeletal muscle consisting of human aligned myofibers with interspersed endothelial networks. To create bio-artificial muscle (BAM), human muscle progenitor cells are cocultured with human umbilical vein endothelial cells (HUVECs) in a fibrin hydrogel. The cell-gel mix is cast into silicone molds with end attachment sites and cultured in endothelial growth medium (EGM-2) for 1 week. The passive forces generated in the contracted hydrogel align the myogenic cells parallel to the long axis of the contracted gel such that they fuse into aligned multinucleated myofibers. This results in the formation of a $2 \mathrm{~cm}$ long and $\sim 1.5 \mathrm{~mm}$ tick human BAM construct with endothelial networks.
\end{abstract}

Key words Coculture, Tissue engineering, Skeletal muscle, Myoblasts, Endothelial cells, Bio-artificial

1 Introduction

Skeletal muscle accounts for $40 \%$ of the total body mass and is important for body movement, endocrine release, metabolism, and heat regulation. Skeletal muscle tissue has a high regenerative capacity and is able to renew itself upon injury [1]. This property is due to presence of quiescent satellite cells (SC), stem cells lying between the basement membrane of the muscle fiber and sarcolemma. Upon injury activated SCs migrate to the site of injury and start to proliferate; these cells are also known as myoblasts. Myoblasts are able to fuse with the damaged myofibers or with each other resulting in new myofiber formation and injury repair [2]. However, when muscle loss is too voluminous, endogenous regeneration fails, resulting in scar tissue formation and functional loss. The most commonly used treatment involves muscle flap 
transplantation: transfer of an autologous vascularized and innervated muscle graft from a donor site to the damaged acceptor site. However, these tissues exist in limited quantities, necessitate a second operation to obtain the tissue, and risk morbidity at the donor site [3]. Therefore, other strategies are being explored such as skeletal muscle tissue engineering approaches. Skeletal muscle tissue engineering aims to reproduce the structure and function of muscle in vitro and thus offers the potential to avoid removal of a muscle flap at a donor site. To achieve functional tissue-engineered skeletal muscle, one must recapitulate its complex structure of aligned myofibers and connective tissue. Current tissue engineering approaches use myoblasts or other cells with myogenic properties to develop myofibers in vitro in a $3 \mathrm{D}$ environment. Parallel alignment of muscle fibers is important for muscle function and use of artificial scaffolds may hinder the alignment [4]. Several strategies have been explored to guide myogenic cell alignment [5]. Tissue engineering approaches in a scaffold-free environment can induce alignment as well. This process is driven by cellular contractile force generation due to the presence of two attachment sites. The resulting unidirectional tension induces cell alignment [6-8].

Still, a major shortcoming is the current size of the constructs. The passive diffusion distance of oxygen and nutrients is a few hundred micrometers and cell survival beyond this distance becomes compromised. Implementation of porous scaffolds and prefabricated hollow tubes in the tissue-engineered construct may improve the delivery $[9,10]$. Also, creation of an in vitro vascular network in the construct, a process called pre-vascularization, could be desirable to ensure a higher survival and prolonged function throughout the muscle construct, both for in vitro applications as well as in vivo transplantation studies $[11,12]$. We have previously studied pre-vascularization by self-organization of endothelial cells into vascular networks in the bio-artificial muscle (BAM) model [13].

We describe a coculture skeletal muscle tissue-engineering approach to obtain human skeletal myofibers with interspersed endothelial networks. From human skeletal muscle biopsies, satellite cells are isolated and expanded to several million myoblasts. These myoblasts are cast within a fibrin hydrogel in a $25-\mathrm{mm}$-long silicone mold containing two attachment points. To introduce endothelial networks in the BAM, human umbilical vein endothelial cells (HUVECs) are added to the myoblast-hydrogel mix in a 70-30 myoblast-endothelial cell ratio and cultured in endothelial growth medium (EGM-2) for 1 week. During the course of 1 week, the cell-gel mix contracts to form a muscle bundle with multinucleated myofibers aligned in the direction of the attachment points with interspersed endothelial networks. The resulting construct, with dimensions of $2 \mathrm{~cm}$ long and $1.5 \mathrm{~mm}$ thick, is called a coculture BAM. Besides further development toward regenerative 
medicine, such a muscle model can also be used to study mechanisms underlying myogenesis, vasculogenesis, and drug effects.

\section{Materials}

- Sylgard 184 silicone elastomer kit—component A \& B.

- Analytical balance.

- Spatula.

- Table top centrifuge.

- 20G needle.

- Distilled water.

- Platform shaker.

- $37^{\circ} \mathrm{C}, 5 \% \mathrm{CO}_{2}$ incubator.

- Biology safety cabinet.

- $70 \%$ Ethanol solution.

- Scotch masking tape $18 \mathrm{~mm}$ wide.

- Small dissecting scissors.

- Curved forceps.

- At least two pairs of sterile dissection forceps.

- Sterile cotton gauze.

- Isolation medium-DMEM $+1 \%$ penicillin/streptomycin $(\mathrm{P} / \mathrm{S})$.

- Ice container.

- $60 \mathrm{~mm}$ petri dish.

- Scalpel.

- Stainless steel insect pins.

- $0.1 \%$ gelatin solution.

- Dispase II.

- Collagenase II.

- Weigh boats.

- Medium filtration unit with $0.22 \mu \mathrm{m}$ filter.

- Fetal bovine serum.

- $100 \mu \mathrm{m}$ cell filter.

- Skeletal muscle cell growth medium (SkGM)-SkGM bulletkit.

- Freezing medium-90\% FBS, 10\% dimethylsulfoxide (DMSO).

- $\mathrm{PBS}$ w/o $\mathrm{Ca}^{2+} \mathrm{Mg}^{2+}$.

- 50:50 solution of methanol: acetone.

- Blocking buffer- $1 \times$ PBS, 1\% BSA, 0.2\% Triton X-100. 
- Primary mouse antihuman desmin antibody.

- Alexa fluor labeled secondary anti-mouse antibody.

- 4',6-diamidino-2-phenylindol (DAPI) solution-DAPI $\mathrm{l}: 10000(\mathrm{w} / \mathrm{v})$ in PBS.

- Fluorescence microscope.

- Skeletal muscle fusion medium (SkFM)_DMEM, high glucose with glutamax and pyruvate, $10 \mathrm{ng} / \mathrm{mL}$ animal-free recombinant human epidermal growth factor, $50 \mu \mathrm{g} / \mathrm{mL}$ bovine serum albumin (BSA), $10 \mu \mathrm{g} / \mathrm{mL}$ insulin, $50 \mu \mathrm{g} / \mathrm{mL}$ gentamicin.

- $4 \%$ formaldehyde solution.

- Primary mouse antihuman tropomyosin antibody.

- Commercially available GFP labeled HUVECs.

- Endothelial growth medium 2 (EGM-2)-endothelial basal medium 2 with EGM 2 singlequot kit supplements \& growth factors.

- Aluminum casting mold and screws.

- Dish soap.

- Drying oven.

- Vacuum aspirator.

- Flat screw driver.

- Pincers.

- Ruler.

- Silicone glue.

- $37^{\circ} \mathrm{C}$ warm water bath.

- Thrombin.

- Fibrinogen.

- Aprotinin.

- Tranexamic acid.

- Dentistry tooth hook.

- 15 and $50 \mathrm{~mL}$ centrifuge tubes.

- Sterile pipets, various sizes.

- 6 and 24-well cell culture plates.

- T25, T75, and T175 cell culture flasks.

\section{Methods}

3.1 Coating of SixWell Plate with Sylgard Silicone Elastomer
1. Weigh $30 \mathrm{~g}$ of component A (Sylgard 184 silicone elastomer kit) per six-well plate on an analytical balance (see Note 1).

2. Pipet component $B$ in a 10:1 (A:B) ratio in the tube and stir with spatula until well mixed. 
3. Centrifuge at $4500 \times \mathfrak{g}, 5 \mathrm{~min}$ at room temperature $(\mathrm{RT})$ to remove air bubbles.

4. Slowly pour elastomer to each six-well, while holding a ruler against the six-well to obtain $5 \mathrm{~mm}$ silicone coating.

5. Remove air bubbles with $20 \mathrm{G}$ needle.

6. Allow to cure for $24 \mathrm{~h}$ at room temperature.

7. Rinse each well three times with distilled water.

8. Fill each well with distilled water and place the six-well plate closed on platform shaker at low setting for $1 \mathrm{~h}$.

9. Drain wells, refill with distilled water, and place overnight in $37^{\circ} \mathrm{C}$ incubator.

10. Drain molds in biological safety cabinet, refill with $70 \%$ ethanol solution, and incubate for at least $1 \mathrm{~h}$. Also sterilize the lids with $70 \%$ ethanol.

11. Drain molds and lids well and air dry in biological safety cabinet.

12. Seal the six-well plate with masking tape and store at RT.

\subsection{Isolation of Myoblasts from Human Biopsy (See Note 2)}

1. Obtain fresh human muscle tissue biopsy (see Note 3), 200-1000 mg wet weight and transfer muscle strip with sterile dissection forceps in a $50 \mathrm{~mL}$ tube with chilled $20 \mathrm{~mL}$ DMEM $+1 \% \mathrm{P} / \mathrm{S}$ kept on ice in the ice container. Keep the muscle biopsies at $4{ }^{\circ} \mathrm{C}($ see Note 4$)$.

2. Working under sterile conditions in a biological safety cabinet, transfer muscle tissue with sterile dissection forceps to a $60 \mathrm{~mm}$ petri dish in $2 \mathrm{~mL} \mathrm{DMEM}+1 \% \mathrm{P} / \mathrm{S}$.

3. Using sterile forceps and scalpel, carefully remove excess connective tissue and fat from tissue sample.

4. Weigh tissue in a clean, covered sterile $60 \mathrm{~mm}$ petri dish with 1-2 $\mathrm{mL}$ sterile DMEM $+1 \% \mathrm{P} / \mathrm{S}$. Tare the balance first using the same $60 \mathrm{~mm}$ petri dish.

5. Using sterile scalpel, cut tissue into strips approximately $2 \mathrm{~mm} \times 10 \mathrm{~mm}$.

6. Using sterile dissection forceps and sterile stainless-steel insect pins, pin strips into sterile sylgard coated six-well plate wells (see Subheading 3.1) under tension, with one pin at each end of strip, and 3-5 strips in each well.

7. Pipet $6 \mathrm{~mL}$ of $\mathrm{DMEM}+1 \% \mathrm{P} / \mathrm{S}$ into each six-well.

8. Place six-well plate containing tissue strips in $37{ }^{\circ} \mathrm{C}, 5 \% \mathrm{CO}_{2}$ incubator.

9. After $24 \mathrm{~h}$, remove medium and add fresh $\mathrm{DMEM}+\mathrm{l} \% \mathrm{P} / \mathrm{S}$, $6 \mathrm{~mL} /$ well. 
10. 48-72 h after pinning strips in plate, digest tissue as outlined below.

11. Coat a T25 tissue culture flask with $0.1 \%$ gelatin solution (see Subheading 3.6).

12. Calculate volume of enzyme solution: For each digestion step, this will be $10 \mathrm{~mL}$ for the first $200 \mathrm{mg}$ of tissue, $+5 \mathrm{~mL}$ for each additional $100 \mathrm{mg}$. If weight of biopsy is less than $200 \mathrm{mg}$, use $10 \mathrm{~mL}$ of enzyme solution for each digestion. Make up $2 \times$ calculated amount (two digestion steps) for each biopsy to be digested.

13. Calculate amount of collagenase needed to give $0.1 \%$ final concentration. Calculate amount of dispase to give a final concentration of $4 \mathrm{mg} / \mathrm{mL}$.

14. Working in biological safety cabinet, pipet required amount of DMEM into sterile bottle. Add weighed dispase to DMEM in container, rinsing weigh boat using DMEM in bottle. Add weighed collagenase to DMEM in container, rinsing weigh boat using DMEM in bottle. Mix enzyme solution by inverting gently a few times. Filter through medium filtration unit with $0.22 \mu \mathrm{m}$ filter. Label bottle and keep on ice.

15. Remove strips from six-well plate using sterile forceps and place in a $15 \mathrm{~mL}$ tube with calculated amount of enzyme solution.

16. Digest for $1 \mathrm{~h}$ in $37{ }^{\circ} \mathrm{C}, 5 \% \mathrm{CO}_{2}$ incubator (see Note 5).

17. Remove the supernatant from $15 \mathrm{~mL}$ tube and place in a sterile $50 \mathrm{~mL}$ tube. Add $10 \%(\mathrm{v} / \mathrm{v})$ of chilled FBS to tube. Chill tube on ice.

18. Place fresh dispase/collagenase enzyme solution in $15 \mathrm{~mL}$ tube with remaining tissue.

19. Digest for $1 \mathrm{~h}$ in $37^{\circ} \mathrm{C}, 5 \% \mathrm{CO}_{2}$ incubator (see Note 5 ).

20. Transfer digest and digested tissue to a $100 \mu \mathrm{m}$ cell filter and pool filtrate with previous digest (see Note 6). Add chilled FBS to tube, $10 \%(\mathrm{v} / \mathrm{v})$ of second digest volume.

21. Rinse filter with another $5 \mathrm{~mL} \mathrm{DMEM}+1 \% \mathrm{P} / \mathrm{S}$.

22. Pellet cells from digests for $5 \mathrm{~min}$ at $200 \times g$ in centrifuge.

23. Suspend cells in $37^{\circ} \mathrm{C}$ pre-warmed $7 \mathrm{~mL}$ SkGM medium and plate in the $0.1 \%$ gelatin-coated T25 tissue culture flask for expansion. Refresh medium every 2 days.

24. Expand cells until $70 \%$ confluency is reached. Split cells, count the number of cells, freeze cells in freezing medium. 


\subsection{Human Muscle Biopsy Characterization: Determination of Myoblast Percentage}

\subsection{Human Muscle Biopsy Characterization: Determination of Myoblast Fusion Index}

1. Seed 5000 cells per well (at least two wells) in a 24-well plate.

2. When the cells have reached $50 \%$ confluency, remove from incubator.

3. Rinse the cells $3 \times 5 \mathrm{~min}$ with PBS at RT and fix for $10 \mathrm{~min}$ at $-20{ }^{\circ} \mathrm{C}$ with a 50:50 solution of acetone: methanol. Wash three times for 5 min with PBS.

4. Incubate the cells for $\mathrm{l} \mathrm{h}$ with blocking buffer at RT.

5. Incubate one well overnight $(\mathrm{O} / \mathrm{N})$ with primary mouse antihuman desmin antibody (1:100 in blocking buffer) and one well in blocking buffer as negative control.

6. Rinse the cells $3 \times 5$ min with PBS at RT.

7. Incubate the cells for $30 \mathrm{~min}$ with Alexa fluor labeled secondary anti-mouse antibody (1:200 in PBS).

8 . Rinse the cells $3 \times 5 \mathrm{~min}$ with $\mathrm{PBS}$ at $\mathrm{RT}$.

9. Incubate the cells for $30 \mathrm{~min}$ with DAPI solution at RT.

10. Replace the DAPI solution by PBS.

11. Count the number of desmin positive cells with a fluorescence microscope (see Fig. la).

12. Count the total number of DAPI stained nuclei in the same field.

13. Repeat previous two steps for a total of at least five microscope fields.

14. Calculate the percentage of myoblasts in each field by dividing the number of desmin positive cells by the total number of nuclei (see Note 7).

1. Seed 50,000 cells per well (at least two wells) in a 24-well plate.

2. Continue to expand the cells, refresh SkGM medium every 2 days until the wells are $80 \%$ confluent.

3. Change the medium to SkFM ( $1 \mathrm{~mL} /$ well) for 4 days, changing medium every second day.

4. Rinse the cells $3 \times 5$ min with PBS at RT.

5. Fix cells for $10 \mathrm{~min}$ at RT with $4 \%$ formaldehyde solution.

6. Rinse the cells $3 \times 5$ min with PBS at RT.

7. Fix cells for $10 \mathrm{~min}$ at $-20{ }^{\circ} \mathrm{C}$ with methanol.

8. Rinse the cells $3 \times 5$ min with PBS at RT.

9. Incubate the cells for $1 \mathrm{~h}$ with blocking buffer at RT.

10. Incubate one well $\mathrm{O} / \mathrm{N}$ with primary mouse antihuman sarcomeric tropomyosin antibody (1:100 in blocking buffer) and one well in blocking buffer as negative control.

11. Rinse the cells $3 \times 5$ min with PBS at RT. 

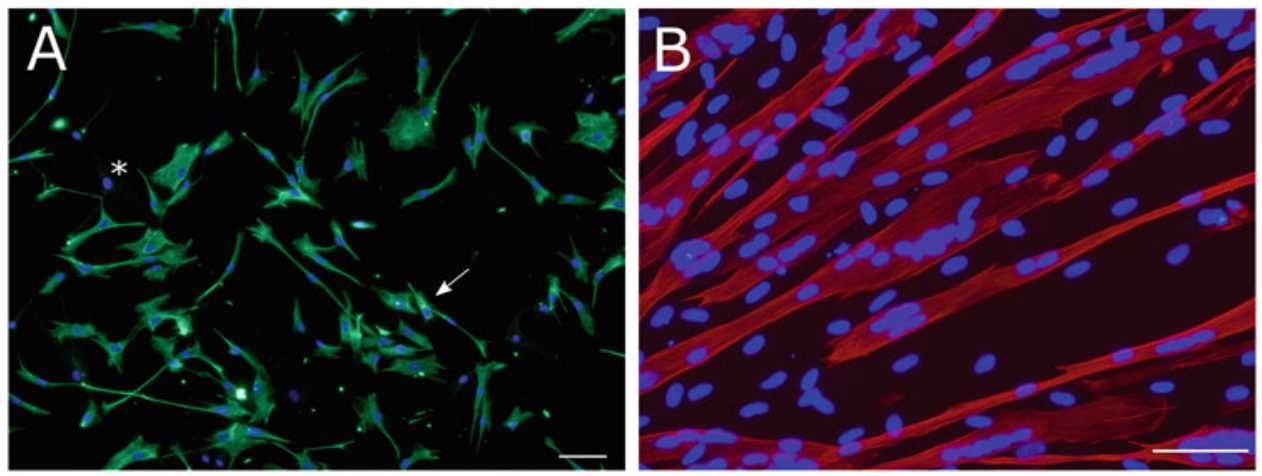

Fig. 1 Human muscle biopsy characterization (a) Desmin immunofluorescence staining (green) and nuclear staining (DAPI, blue). The asterisk indicates a nucleus from a desmin negative (non-myogenic) cell, the arrow indicates a nucleus from a desmin-positive myoblast. (b) After 4 days in SkFM, positive tropomyosin staining (red) and cell fusion indicates efficient differentiation to muscle fibers. Scale bar represents $50 \mu \mathrm{m}$

\subsection{Human Muscle}

\section{Biopsy}

Characterization:

Determination

of Doubling Time
12. Incubate the cells for $1 \mathrm{~h}$ with Alexa fluor labeled secondary anti-mouse antibody (1:200 in PBS).

13. Rinse the cells $3 \times 5$ min with PBS at RT.

14. Incubate the cells for $30 \mathrm{~min}$ with DAPI solution at RT.

15. Count the number of nuclei in tropomyosin positive myofibers with a fluorescence microscope (see Fig. Ib).

16. Count the total number of DAPI stained nuclei in the same field.

17. Repeat previous two steps for a total of at least five microscope fields.

18. Calculate the fusion index, the percent of myoblasts which have fused by dividing the number of nuclei in tropomyosin positive cells/field by the total number of myoblasts/field (total number of nuclei/field multiplied by the percent myoblasts in the field as determined by desmin staining) ( see Note 7).

1. Plates 125,000 muscle cells in a T25 culture flask with $7 \mathrm{~mL} \mathrm{SkGM.}$

2. Refresh medium every 2 days.

3. When $70 \%$ confluency is reached, split cells, count the number of cells, and plates 125,000 muscle cells in a fresh T25 culture flask with $7 \mathrm{~mL}$ SkGM medium.

4. Determine doubling time $=L N$ (number of cells at passage $(X+1) /$ number of cells at passage $(X)(=125,000)) / L N(2)$.

5 . Keep repeating the previous four steps until the doubling time exceeds $50 \mathrm{~h}$. This gives the doubling time and the maximum number of doublings the cells may reach (see Note 7). 


\subsection{Culture and Expansion of HUVECS}

3.7 Production of Six Wells with Silicone Molds and Attachment Sites
1. Coat a T25 or a T75 tissue culture flask with $0.1 \%$ gelatin solution. Therefore add $4 \mathrm{~mL}$ of $0.1 \%$ gelatin solution in flask and incubate for $\mathrm{l} \mathrm{h}$ in incubator at $37^{\circ} \mathrm{C}, 5 \% \mathrm{CO}_{2}$. Remove gelatin solution, wash two times with PBS, and add $4 \mathrm{~mL}$ cell culture medium to pre-incubate the flask for cell seeding. Keep in the incubator at $37^{\circ} \mathrm{C}, 5 \% \mathrm{CO}_{2}$.

2. Thaw commercially acquired HUVECs and seed them in a T25 gelatin-coated flask. Change EGM-2 medium every other 2 days until $80 \%$ confluency is reached.

3. Subculture the HUVECs on gelatin-coated T75 flasks in a $1: 4$ ratio until passage 6 . Use HUVECs at maximum passage 7 for tissue engineering.

1. Soak metal casting mold (two pieces, see Fig. 2 a) in a $5 \%$ dish soap in water.

2. Dry casting mold in $40{ }^{\circ} \mathrm{C}$ oven (see Note 8). Remove mold when it is dry. Assemble mold by using long screws (see Fig. 2b) (see Note 9).

3. Combine $20 \mathrm{~g}$ of component $\mathrm{A}$ and $2 \mathrm{~g}$ of component $\mathrm{B}$ (Silicone Elastomer kit) in a $50 \mathrm{~mL}$ centrifuge tube and stir with spatula until well mixed (see Note 1 ).

4. Centrifuge at $4500 \times g$ for $5 \mathrm{~min}$ at RT to remove the big air bubbles.

5. Use a vacuum system to remove the small air bubbles.

6. Over-fill the casting mold by pouring slowly silicone elastomer in the casting mold (should be convex meniscus) (see Fig. 2c).

7. With $22 \mathrm{G}$ needle, remove air bubbles.

8. Dry molds for $15 \mathrm{~min}$ in $150{ }^{\circ} \mathrm{C}$ oven.

9. Keep the casting molds overnight at RT to let the silicone elastomer cure.

10. Unscrew the screws and separate casting mold pieces by using a flat screw driver to create a lever system. Use a scalpel to remove excess silicone from the casting piece with the silicone molds ( see Note 10). Go underneath the silicone layer with the scalpel and follow the contours of the casting mold (see Fig. 2d). Release the silicone molds from the casting mold pieces, resulting in separate silicone tissue molds (see Fig. 2e).

11. Remove excess silicone from around tissue molds.

12. To clean silicone molds, rinse each mold three times with distilled water for $5 \mathrm{~min}$.

13. Place $1.4 \mathrm{~cm}$ long stainless steel pins at a distance of $2 \mathrm{~cm}$ in silicone tissue molds ( see Note 11 ). 

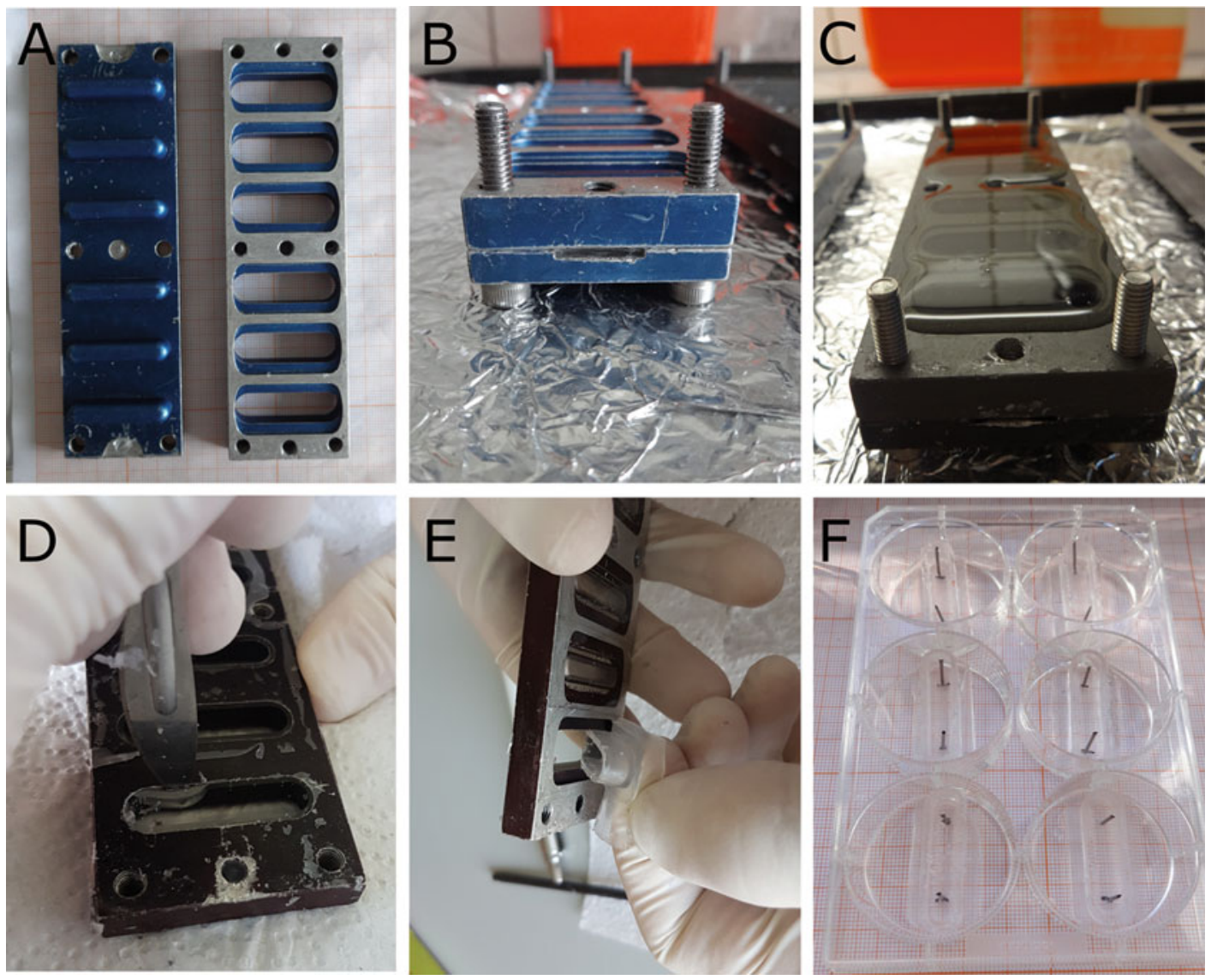

Fig. 2 Production of six wells with silicone molds and attachment sites (a) Casting mold consisting of two metal pieces (b) Assembled casting mold pieces (c) Casting mold overfilled with silicone elastomer (d) Detachment of silicone mold from casting mold with a scalpel (e) Release of silicone mold from the casting mold (f) six-well plate with silicone molds and attachment sites

14. Using a thin film of silicone glue, coat the bottom of the silicone mold and the insertion place in the six-well and place in center of six-well plate (see Fig. 2f).

15. Allow $24 \mathrm{~h}$ for glue to cure.

16. Rinse each mold three times with distilled water for $5 \mathrm{~min}$.

17. Fill each well with distilled water and place on platform shaker at low setting for $1 \mathrm{~h}$.

18. Drain wells, refill with distilled water, and place overnight in $37^{\circ} \mathrm{C}$ incubator.

19. Drain molds well under sterile conditions in biological safety cabinet, refill with $70 \%$ ethanol solution, and incubate at least $1 \mathrm{~h}$.

20. Drain molds well and air dry in biological safety cabinet.

21. Seal the six-well plate with masking tape and store at RT. 


\subsection{Tissue Engineering of Coculture Bioartificial Muscle (BAM)}

1. Calculate the required number of cells: Count per BAM 600,000 GFP labeled human umbilical vein derived endothelial cells (HUVECs) and $1.4 \times 10^{6}$ muscle cells (see Note 12).

2. Final concentration of fibrin in BAM is $1 \mathrm{mg} / \mathrm{mL}$ fibrinogen and $2 \mathrm{U} / \mathrm{mL}$ thrombin, but $1 / 2$ of final volume of gel is fibrinogen and $1 / 2$ of final volume of gel is thrombin, so two times terminal dilution. Final volume of gel per BAM is $1 \mathrm{~mL}$. Calculate the required volume of $2 \mathrm{mg} / \mathrm{mL}$ fibrinogen solution and $4 \mathrm{U} / \mathrm{mL}$ thrombin solution (see Note 12 ).

3. Work at RT and in biology safety cabinet to keep everything sterile.

4. Start with cell pellet of GFP labeled HUVECs and muscle cells.

5. Prepare $2 \mathrm{mg} / \mathrm{mL}$ fibrinogen solution:

Thaw the fibrinogen stock ( see Note 13 ) in a warm water bath at $37{ }^{\circ} \mathrm{C}(10 \mathrm{mg} / \mathrm{mL})$ (see Note 14$)$ and dilute five times in DPBS with $\mathrm{Ca}^{2+}$ and $\mathrm{Mg}^{2+}$.

6. Prepare $4 \mathrm{U} / \mathrm{mL}$ Thrombin Solution:

Dilute the thrombin stock $(1000 \mathrm{U} / \mathrm{mL}) 250$ times in DPBS with $\mathrm{Ca}^{2+}$ and $\mathrm{Mg}^{2+}$.

7. Mix cell pellet with thrombin solution and add $0.5 \mathrm{~mL}$ of the cell-thrombin mix to the silicone mold (see Note 15).

8. Add $0.5 \mathrm{~mL} 2 \mathrm{mg} / \mathrm{mL}$ fibrinogen solution to the silicone mold: pipet three times up and down, and around the attachment sites.

9. Keep the BAMs 10 min on the bench at RT and then transfer them to $37{ }^{\circ} \mathrm{C}, 5 \% \mathrm{CO}_{2}$ incubator.

10. After $2 \mathrm{~h}$ : add $10 \mathrm{~mL}$ of EGM-2 medium with aprotinin (final concentration $92.5 \mu \mathrm{g} / \mathrm{mL}$ ) and tranexamic acid (final concentration $400 \mu \mathrm{M}$ ) per BAM (see Note 16) (see Fig. 3a).

11. 1 and 2 days post-casting: detach fibrin gel from silicone mold with dentistry tooth hook (see Notes 17 and 18) (see Fig. 3b).

12. Refresh EGM-2 medium every 2 days (see Note 16).

13. 7 days post-casting a BAM is formed with dimensions of $2 \mathrm{~cm}$ long and $1.5 \mathrm{~mm}$ thick with aligned multinucleated myofibers and GFP labeled interspersed endothelial networks (see Fig. 3c, d).

\section{Notes}

1. Component $\mathrm{A}$ is very viscous and it is not possible to use a pipette. Therefore, pour component $\mathrm{A}$ in a (tared) $50 \mathrm{~mL}$ centrifuge tube and determine the exact amount by weight; this may be slightly more than $30 \mathrm{~g}$. 

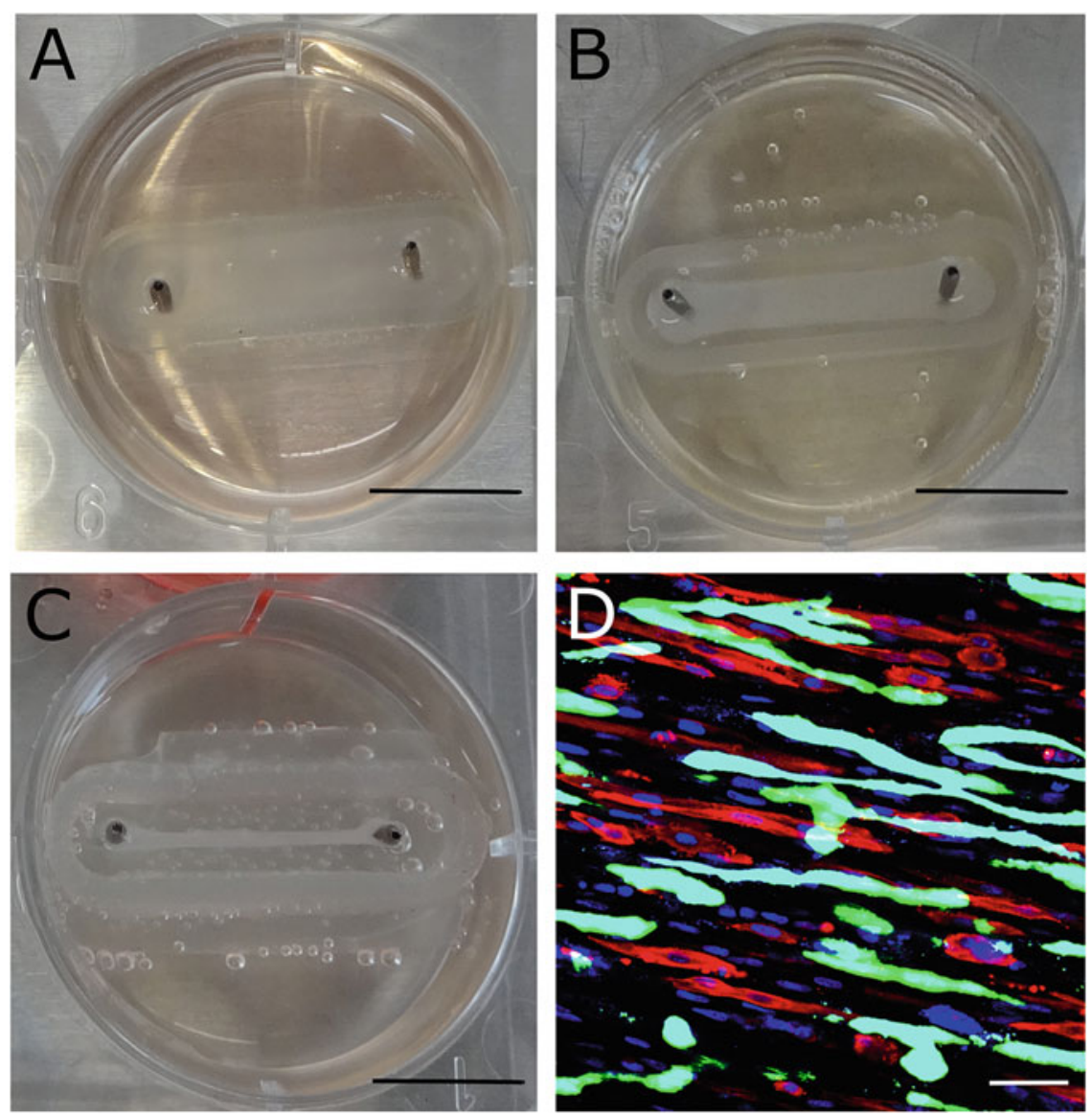

Fig. 3 Tissue engineering of coculture bioartificial muscle over 1 week time-course (a) Two hours postcasting, the cell-fibrin solution has gelled and EGM-2 medium is added in the six-well. (b) One-day postcasting, detachment of the gelated cell-fibrin solution results in formation of a contracting muscle bundle. (c) One-week post casting, cell-driven contraction of the fibrin hydrogel results in the formation of a $2 \mathrm{~cm}$-long and $\sim 1.5 \mathrm{~mm}$-tick human BAM construct. (d) Confocal microscopy image of 1 week old 3D coculture BAM shows tropomyosin positive (red) aligned multinucleated (DAPI, blue) myofibers with interspersed GFP-labeled endothelial networks (green). Black scale bars represent $1 \mathrm{~cm} \mathrm{(a-c),} \mathrm{white} \mathrm{scale} \mathrm{bar} \mathrm{(d)} 50 \mu \mathrm{m}$

2. This protocol can be omitted if myoblasts are obtained from a commercial source.

3. Perform the muscle biopsy under sterile conditions. Wear sterile gloves, sterile coat, a mouth mask and work with a sterile bed to store your instruments during the biopsy.

Cut through the muscle fascia very carefully so that you do not damage the underlying muscle fibers.

4. It is best to start the myoblast isolation directly after the muscle biopsy, but it is possible to keep the biopsy up to $48 \mathrm{~h}$ in $\mathrm{DMEM}+1 \% \mathrm{P} / \mathrm{S}$ at $4{ }^{\circ} \mathrm{C}$. 


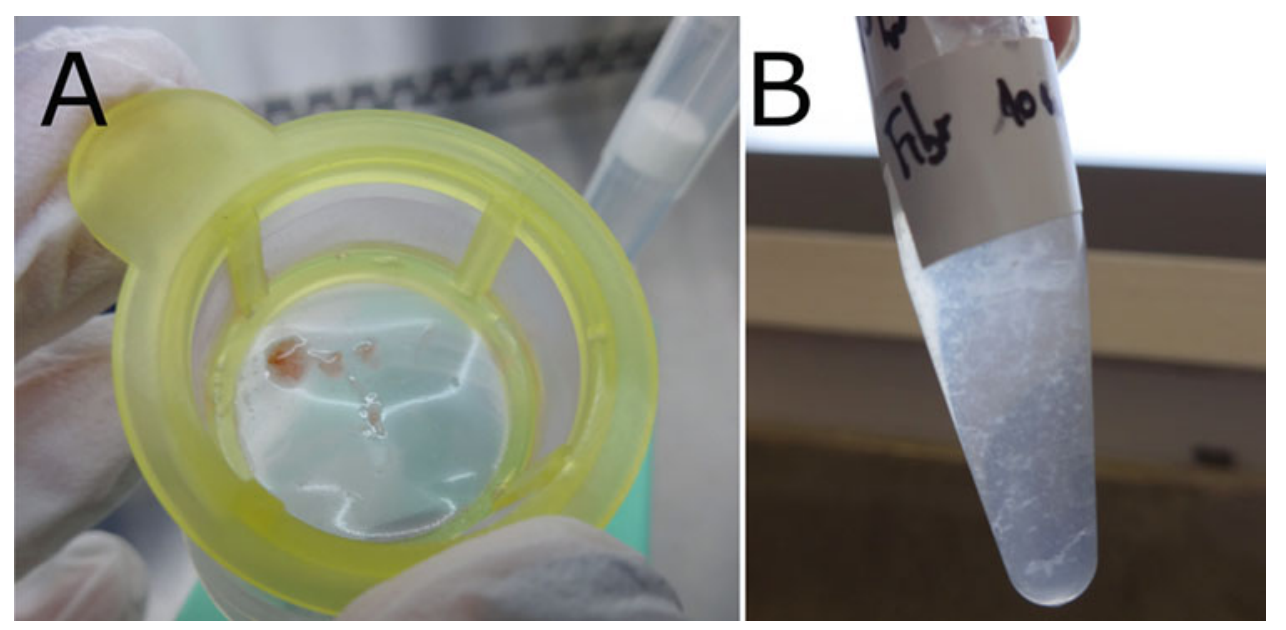

Fig. 4 Troubleshooting: see Notes 6 and 14 (a) $100 \mu \mathrm{m}$ cell filter showing digested human muscle tissue depicted as a thread structure (see Note 6). (b) Thawed fibrinogen solution in warm water bath at $37{ }^{\circ} \mathrm{C}$ showing partly clotted fibrinogen visible as white fibrin flakes (see Note 14)

5. Keep the $15 \mathrm{~mL}$ tube on the side so every strip is surrounded by the enzyme solution.

6. If the digestion went well, then the remaining tissue on the $100 \mu \mathrm{m}$ filter is a thread (see Fig. 4a).

7. Advisable requirements for isolated muscle cell population: $>$ $60 \%$ desmin positive myoblasts, a fusion index higher than $60 \%$, and a population doubling time lower than $50 \mathrm{~h}$.

8. Transfer the pre-soaked casting molds immediately to the dry oven at $40{ }^{\circ} \mathrm{C}$.

9. The casting mold will feel a little bit greasy.

10. Remove excess silicone from the side of the casting mold that is the upper side of the silicone mold.

11. To obtain stainless steel pins, cut $4 \mathrm{~cm}$ long $20 \mathrm{G}$ syringe needles in $1.4 \mathrm{~cm}$ long pins by using pincers. To keep the steel pins at their place in the silicone molds, prick the pins slightly through the silicone molds.

12. Calculate $10 \%$ extra of total amount for cells, thrombin and fibrinogen solution.

13. Fibrinogen stock preparation: Warm $5 \mathrm{~mL}$ sterile demi water and $15 \mathrm{~mL}$ of DPBS (with $\mathrm{Ca}^{2+}, \mathrm{Mg}^{2+}$ ) in warm water bath at $37{ }^{\circ} \mathrm{C}$. Check label of fibrinogen powder for reconstitution volume. The volume of demineralized water to be added to fibrinogen powder is: reconstitution volume $(\mathrm{mL}) \times(\mathrm{mg}$ fibrinogen)/1000. Working in a biological safety cabinet, add specified reconstitution volume of warm demi $\mathrm{H}_{2} \mathrm{O}$ to fibrinogen. Place tube in a warm water bath at $37^{\circ} \mathrm{C}$. Do not disturb until 
completely dissolved - this will take 15 min or longer. When dissolved, add $0.316 \mathrm{~mL} \times(\mathrm{mg}$ fibrinogen/100) of 10,000 $\mathrm{KIU} / \mathrm{mL}$ aprotinin to fibrinogen. Final volume in $\mathrm{mL}$ is (mg fibrinogen)/10. Make solution up to the final volume by adding warm DPBS. Mix gently by pipetting up and down-do not vortex! Final concentration of fibrinogen will be $10 \mathrm{mg} /$ $\mathrm{mL}$. Final concentration of aprotinin will be $316 \mathrm{KIU} / \mathrm{mL}$. Aliquot into required volumes for tissue engineering-usually $1 \mathrm{~mL}$-in sterile $1.5 \mathrm{~mL}$ eppendorf tubes. Store at $-80^{\circ} \mathrm{C}$ for maximum 1 year.

14. Make sure the thawed fibrinogen solution is clot free. In case of clotting, thaw a new vial (see Fig. 4b).

15. When adding the cell-thrombin mix to the mold, make sure it is also distributed around the attachment sites.

16. Don't pipet on the BAM, but pipet into the six-well plate. Make sure the medium in the six-well plate is in contact with the BAM in the silicone mold.

17. Be careful not to damage the BAM. Follow the contours of the silicone mold. Detach also the bottom of the BAM from the mold. If the detachment went well, there will be no little pieces of fibrin coming loose and also $10 \mathrm{~min}$ after detachment a bundle will appear (see Fig. 3b).

18. Two days post-casting a contracted hydrogel can be observed. In the following days more cell-driven hydrogel contraction will occur.

\section{Acknowledgments}

This work was funded by AFM-Telethon trampoline grant 19802 and the Research Foundation-Flanders (FWO) grant 1529817N.

\section{References}

1. Frontera WR, Ochala J (2015) Skeletal muscle: a brief review of structure and function. Calcif Tissue Int 96:183-195

2. Abmayr SM, Pavlath GK (2012) Myoblast fusion: lessons from flies and mice. Development 139:641-656

3. Agostini T, Lazzeri D, Spinelli G (2013) Anterolateral thigh flap: systematic literature review of specific donor-site complications and their management. J Cranio-Maxillofac Surg 41:15-21

4. Thorrez L, Shansky J, Wang L et al (2008) Growth, differentiation, transplantation and survival of human skeletal myofibers on biodegradable scaffolds. Biomaterials 29:75-84

5. Cittadella Vigodarzere G, Mantero S (2014) Skeletal muscle tissue engineering: strategies for volumetric constructs. Front Physiol 5:362

6. Thorrez L, Vandenburgh H, Callewaert $\mathrm{N}$ et al (2006) Angiogenesis enhances factor IX delivery and persistence from retrievable human bioengineered muscle implants. Mol Ther 14:442-451

7. Vandenburgh HH, Karlisch P, Farr L (1988) Maintenance of highly contractile tissuecultured avian skeletal myotubes in collagen gel. In Vitro Cell Dev Biol 24:166-174 
8. Powell C, Smiley BL, Mills J et al (2002) Mechanical stimulation improves tissueengineered human skeletal muscle. Am J Physiol Cell Physiol 283:1557-1565

9. Walthers C, Nazemi A, Patel SL, Wu BM, Dunn JC (2014) The effect of scaffold macroporosity on angiogenesis and cell survival in tissue-engineered smooth muscle. Biomaterials 35:5129-5137

10. Takei T, Kitazono Z, Ozuno Y et al (2015) Vascular-like network prepared using hollow hydrogel microfibers. J Biosci Bioeng 121:336-340
11. Kaully T, Kaufman-Francis K, Lesman A et al (2009) Vascularization-the conduit to viable engineered tissues. Tissue Eng Part B Rev 15:159-169

12. Levenberg S, Rouwkema J, Macdonald M et al (2005) Engineering vascularized skeletal muscle tissue. Nat Biotechnol 23:879-884

13. Gholobova D, Decroix L, Van Muylder V et al (2015) Endothelial network formation within human tissue-engineered skeletal muscle. Tissue Eng Part A 21:2548-2558 